\title{
Microwave-Mediated Rapid Synthesis of Gold Nanoparticles Using Calotropis procera Latex and Study of Optical Properties
}

\author{
Ratul Kumar Das, ${ }^{1}$ Punuri Jayasekhar Babu, ${ }^{1,2}$ Nayanmoni Gogoi, ${ }^{1}$ \\ Pragya Sharma, ${ }^{1}$ and Utpal Bora ${ }^{1,2}$ \\ ${ }^{1}$ Biotech Hub, Centre for the Environment, Indian Institute of Technology Guwahati, Assam, Guwahati 781039, India \\ ${ }^{2}$ Biomaterials and Tissue Engineering Laboratory, Department of Biotechnology, Indian Institute of Technology Guwahati, \\ Assam, Guwahati 781039, India
}

Correspondence should be addressed to Utpal Bora, ubora@iitg.ernet.in

Received 21 September 2012; Accepted 15 October 2012

Academic Editors: A. Datta, A. Kajbafvala, and S.-H. Kim

Copyright ( 2012 Ratul Kumar Das et al. This is an open access article distributed under the Creative Commons Attribution License, which permits unrestricted use, distribution, and reproduction in any medium, provided the original work is properly cited.

We report a microwave-mediated simple and rapid method of gold nanoparticles (GNPs) synthesis using latex of Calotropis procera. UV-Vis spectroscopic studies indicated the formation of GNPs. The GNPs were stable at room temperature $\left(25^{\circ} \mathrm{C}\right)$ for six months. Transmission electron microscope (TEM) micrographs of the synthesized GNPs showed the formation of spherical nanoparticles with an average size of $13 \pm 5 \mathrm{~nm}$. SAED and XRD confirmed the crystalline nature of GNPs. Fourier transform infrared (FTIR) analysis indicated the presence of organic coating on the nanoparticles. Cytotoxicity of the GNPs was tested on HeLa and A549 and found to be nontoxic which was indicating that latex of Calotropis procera provided the nontoxic coating on GNPs, thus can be used as biomedical and pharmacological applications.

\section{Introduction}

Gold nanoparticles (GNPs) have been of immense interest for their unique chemical and physical properties and potential technological applications in various fields ranging from catalysis to disease diagnosis [1-15]. Conventional methods of GNPs synthesis mostly rely on the use of synthetic chemicals and prolonged heating [16-19]. Owing to the increased awareness for potential toxicity of GNPs associated with biological applications, alternative methodologies for biocompatible GNPs synthesis are gaining importance. Replacement of toxic chemicals as a reducing and stabilizing agent is the prime concern of this new approach. Reports about the successful synthesis and subsequent stability of GNPs by using different biomaterials sourced from plant and microbes are now increasing day by day [20-27]. On the other hand, microwave (MW) dielectric heating is a fast emerging and widely accepted new processing technology for a variety of inorganic synthesis and biomedical applications [28-33]. Compared to the conventional heating, MW irradiation shortens reaction times and improve yield without causing any appreciable alteration in the composition of products of a chemical reaction. In contrast to general heating treatment, MW synthesis favors homogeneous heating through the entire bulk of the reaction mixture in a container, leading to a more homogeneous and easy nucleation of noble metal nanoparticles [34-37].

We found that latex of the plant C. procera, a multifarious plant having many remedial properties, can act as both reducing and capping agent in the GNPs synthesis through conventional heating [38]. This motivated us to further explore the synthesis of GNPs through MW irradiation. We found remarkable shortening in the reaction time and GNPs of reduced diameter as compared to conventional heating method. The approach is a green route for the rapid GNPs synthesis as no hazardous chemicals as a reducing or capping agent are used.

\section{Experimental Section}

Chlorauric acid $\left(\mathrm{HAuCl}_{4}\right)$ was purchased from Sigma (Bangalore, India). Crude latex of $C$. procera was collected in 
distilled water (1:1 ratio) and centrifuged at $5000 \times \mathrm{g}$ at $4^{\circ} \mathrm{C}$ for $10 \mathrm{~min}$ to separate the water insoluble rubber. The supernatant constituting the aqueous fraction (AF) was collected and used for GNPs synthesis. Protein concentration of AF was measured by Folin-Lowry method [39]. GNPs synthesis was carried out in a domestic microwave oven ( $900 \mathrm{~W}, 2.45 \mathrm{GHz}$, LG MO-MC-767 W/WS). To optimize AF concentration, different volumes (for final concentration of $1-5 \%, v / v)$ of $\mathrm{AF}$ were reacted with $1 \mathrm{mM}$ of $\mathrm{HAuCl}_{4}$ aqueous solution and irradiated with MW for 40 seconds. To see the effect of MW irradiation time on the GNPs synthesis process, reaction mixture was irradiated for different time duration (10-60 s) at the maximum power output $(900 \mathrm{~W})$ of the microwave oven.

UV-Vis spectroscopy measurements were carried out on a Carry 100 BIO UV-Vis spectrophotometer (Varian, CA, USA). Morphology and size of GNPs were investigated using JEOL 2100 UHR-TEM instrument. XRD was carried out with a Bruker D8 ADVANCE X-ray powder diffractometer (Bruker AXS Inc.) using CuK $\alpha(\lambda=1.54 \AA)$ source. Test for surface protein adsorption of GNPs was done by treating GNPs solution with strong electrolyte $(10 \% \mathrm{NaCl})$ as described earlier [40]. FT-IR of purified and lyophilized AF and GNPs were done on an infrared spectrophotometer (PerkinElmer, Norwalk, USA).

For cytotoxicity study of GNPs, MTT (3-[4,5-dimethylthiazole-2-yl]-2,5-diphenyl tetrazolium bromide) dye conversion assay [41] was carried out on human cervical (HeLa) and lung carcinoma (A549) cancer cell lines (obtained from NCCS, Pune). After 24 hrs of GNP (5, 10, 20, 40, 50, 100, and $150 \mu \mathrm{M})$ treatment, viability of treated and untreated cells (control) for both cell lines was calculated by the following equation:

$$
\text { Viability }(\%)=\frac{N_{t}}{N_{c}} \times 100,
$$

where $N_{t}$ is the absorbance of the cells treated with GNPs and $N_{c}$ was the absorbance of the untreated cells.

\section{Results and Discussion}

3.1. Influence of Procera Latex (AF) on GNPS Synthesis. We observed that the solution containing unreduced gold ions $\left(\mathrm{Au}^{3+}\right)$ and $\mathrm{AF}$ turned into ruby red after around $40 \mathrm{sec}$ of MW irradiation. UV-Vis scanning of the colored solution in the range of $400-700 \mathrm{~nm}$ exhibited bands for surface plasmon resonance (SPR) indicating the formation of GNPs (Figure 1).

The SPR peaks corresponding to 1 and $2 \%$ of AF against $1 \mathrm{mM}$ of $\mathrm{HAuCl}_{4}$ were located at around 600 and $550 \mathrm{~nm}$, respectively, suggesting the formation of larger GNPs. For 3$5 \%$ of AF, SPR peaks were blue-shifted and located at around $527 \pm 2 \mathrm{~nm}$ which were characteristic of spherical GNPs. As SPR peak position and intensity are indicative of particle size and concentration, respectively, we concluded that AF above 3\% can form GNPs with spherical shape. At 3-5\% $\mathrm{AF}$, differences in SPR peaks and intensity were seen to be negligible and thus $3 \%$ of AF was considered as the optimum

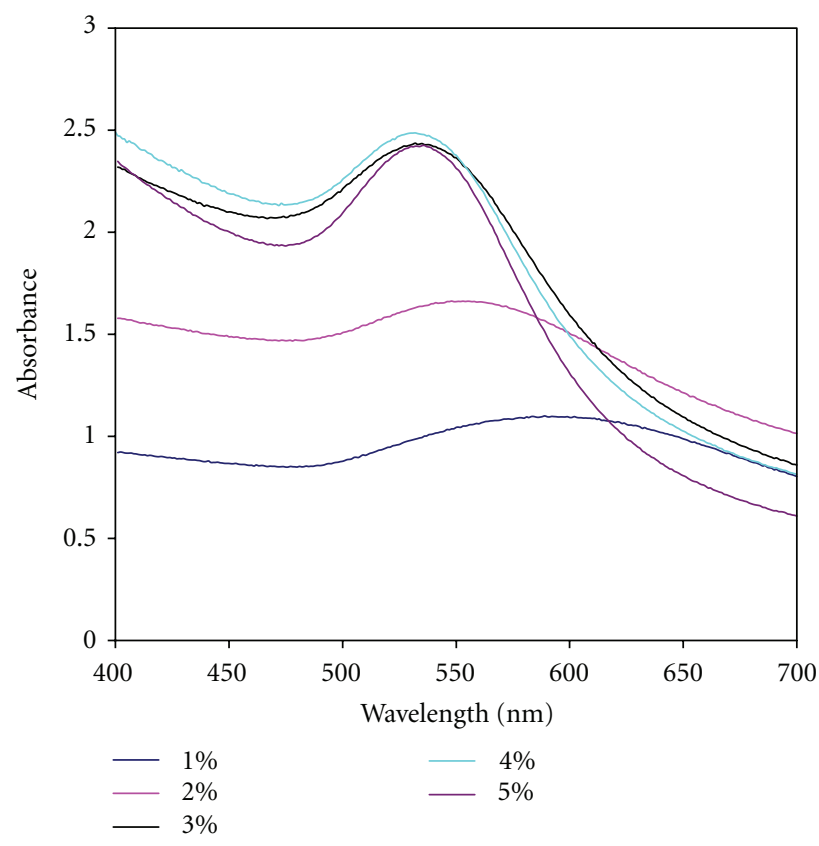

FIGURE 1: UV-Vis-spectra of GNPs synthesized using (a) $1 \mathrm{mM}$ $\mathrm{HAuCl}_{4}$ with different concentrations (1-5\%) of AF.

concentration for efficient reduction of $1 \mathrm{mM} \mathrm{HAuCl}_{4}$ to GNPs.

3.2. Time-Dependant Synthesis of GNPs. MW irradiation time was optimized with this optimized AF concentration. A gradual transition of change in the colour of the reaction mixture obtained at different time of MW irradiation can be seen in the inset of Figure 2. For 10, 20 and $25 \mathrm{~s}$ no SPR peaks were observed. At $30 \mathrm{~s}$ the intensity of SPR band of GNPs was found to be low with a peak around $536 \mathrm{~nm}$, which indicated the formation of spherical particles. With increased MW irradiation from 30 to $40 \mathrm{~s}$, the intensities of SPR bands increased considerably with narrow peaks shifted to 525$530 \mathrm{~nm}$. For 40-60 s irradiations, increase in the SPR band intensities was very low which indicated complete reduction of gold ions. Thus we considered $40 \mathrm{~s}$ of MW irradiation to be optimum for the GNPs synthesis.

3.3. Characterization Studies Revealed Crystalline Nature of GNPs. A representative TEM image and corresponding size distribution histogram of GNPs synthesized with optimized conditions (3\% AF, $40 \mathrm{~s} \mathrm{MW}$ irradiation time) is shown in Figure 3. Spherical particles were more abundant than particles of other shapes (Figure 3(a)). The high-resolution TEM (HRTEM) image displayed clear lattice fringes (Figure 3(b)). Selected-area electron diffraction pattern (SAED) of a single-spherical particle confirmed its crystalline nature (Figure 3(c)). Three Debye-Scherrer's rings corresponding to strong (111), (200), and weak (220) planes of an fcc crystalline lattice were observed. A histogram representing the size distribution of GNPs corresponding to TEM image confirmed a variation in the particle size (Figure $3(\mathrm{~d})$ ). The average particle size was found to be $13 \pm 5 \mathrm{~nm}$. 
TABLE 1: Comparison of the results obtained in conventional heating and MW irradiation of GNPs synthesis.

\begin{tabular}{lcc}
\hline Reaction parameters/properties & \multicolumn{2}{c}{ Method of GNPs synthesis } \\
& Conventional heating & Microwave irradiation \\
\hline $\mathrm{AF}$ concentration (v/v) & $4 \%$ & $3 \%$ \\
$\mathrm{AuCl}_{4}$ concentration & $1 \mathrm{mM}$ & $40 \mathrm{mM}$ \\
Time & 20 minutes & Spherical \\
Shape & Spherical & $13 \pm 5$ \\
Mean diameter of GNPs $(\mathrm{nm})$ & $22 \pm 10$ & Yes \\
Protein capping & Yes & Yes \\
Biocompatibility against tested cell lines & Yes & \\
\end{tabular}

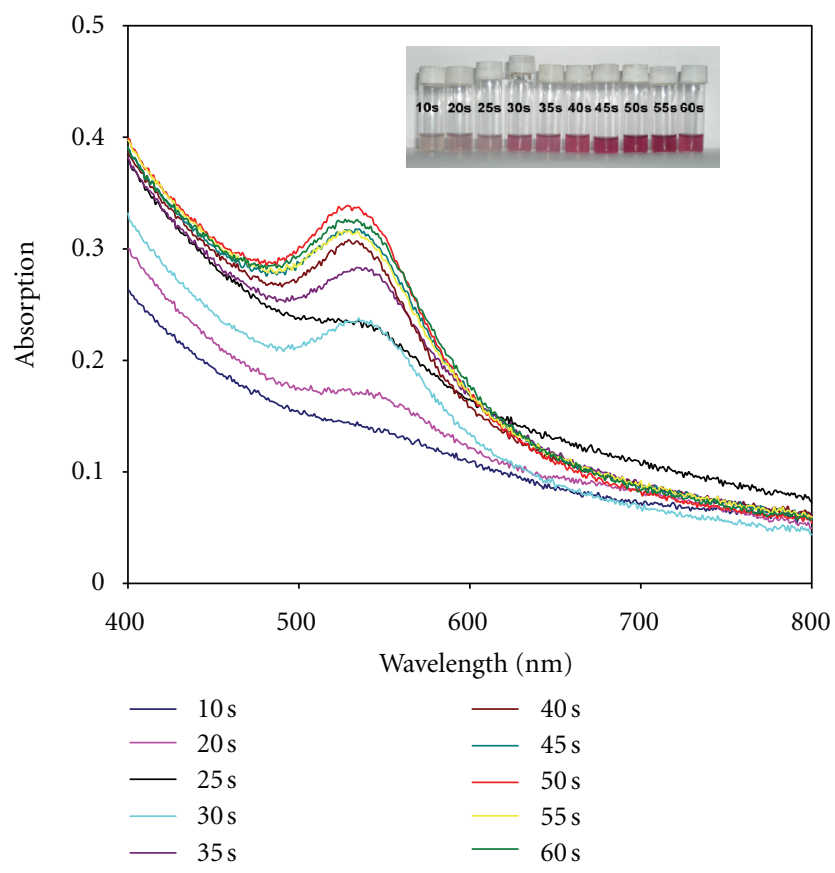

FIGURE 2: UV-Vis-spectra of GNPs synthesized using 3\% latex and $1 \mathrm{mM} \mathrm{HAuCl}_{4}$ at different MW irradiation time duration (10$60 \mathrm{sec}$ ), the inset photo shows respective colour of gold colloidal solution.

XRD patterns of GNPs exhibited three prominent Bragg reflections with $2 \theta$ values at around $38^{\circ}, 44^{\circ}$, and $64^{\circ}$ of lattice planes and were indexed to the (111), (200), and (220) facets of gold, respectively, (Figure 4).

3.4. Possibility of Functional Groups Being Involved in the Reduction of $\mathrm{Au}^{3+}$ Ions to GNPs. The FTIR spectrum (curve 1) of AF showed characteristic IR bands belonging to protein, alcoholic, or phenolic compounds (Figure 5). Broad band at $3360 \mathrm{~cm}^{-1}$ was due to the hydroxyl functional group. Strong absorption bands at 1617 and $1080 \mathrm{~cm}^{-1}$ were characteristic of amide I and $\mathrm{C}-\mathrm{N}$ stretching vibrations of amine, respectively. The band at $1228 \mathrm{~cm}^{-1}$ belongs to amide III. The characteristic peak for amide II seemed to have merged with the intense band of amide I. Band at $2918 \mathrm{~cm}^{-1}$ was assigned to secondary amine and band arising from the $\mathrm{C}=\mathrm{O}$ stretching mode of carboxylic acid can be seen at $1364 \mathrm{~cm}^{-1}$.

FTIR spectrum of Au-NP (curve 2) showed strong bands for amide I $\left(1625 \mathrm{~cm}^{-1}\right), \mathrm{C}=\mathrm{O}$ stretching mode of carboxylic acid, and $\mathrm{C}-\mathrm{N}$ stretching of amines $\left(1373 \mathrm{~cm}^{-1}\right.$ and $\left.1086 \mathrm{~cm}^{-1}\right)$. A comparative analysis of both FTIR spectra (curve 1 and 2) suggested active participation of AF proteins in the bioreduction of chlorauric acid to GNPs. Changes in IR absorption bands and shifts in band positions at 1617 to 1625,1080 to 1086 , and 1364 to $1373 \mathrm{~cm}^{-1}$ supported a dominant role of protein molecules in the synthesis of GNP. Protein estimation $\left(8 \mathrm{mg} \mathrm{mL}^{-1}\right)$ of AF and retention of original colour of GNPs solution even after treatment with strong electrolyte solution $(10 \% \mathrm{NaCl})$, indicated for adsorption of proteins on GNPs surfaces.

3.5. Calotropis procera Provided Nontoxic Coating on GNPs. In cytotoxicity assay, after $24 \mathrm{~h}$ of posttreatment, HeLa and A549 cells showed high viability even up to $150 \mu \mathrm{M}$ exposure of GNPs suggesting that probably protein coating on GNPs provided a nontoxic property (Figure 6). It is worthwhile to mention that a vast majority of gold (I) and gold (III) compounds exhibit varying degrees of cytotoxicity to a variety of cells $[42,43]$. The lack of any noticeable toxicity of the present GNPs proved them to be highly biocompatible and thus provides new opportunities for the drug delivery and molecular imaging (MRI).

We have synthesized GNPs using the aqueous fraction of C. procera by conventional heating. We made a comparison of the two methods, namely, "conventional heating" and "MW irradiation" as shown in Table 1. It can be seen that MW irradiation incredibly took less time, produced smaller sized GNPs, and consumed less AF, while there was no major effect on the shape and biocompatibility. Thus MW irradiation offered a method of rapid synthesis of the finer GNPs over conventional heating.

\section{Conclusions}

The present route for the synthesis of GNP using C. procera latex in combination with MW irradiation is a novel method. The synthesized GNPs were highly stable, crystalline in nature, and had nearly spherical shapes with average diameter of $13 \pm 5 \mathrm{~nm}$. FTIR and protein coagulation test indicated 


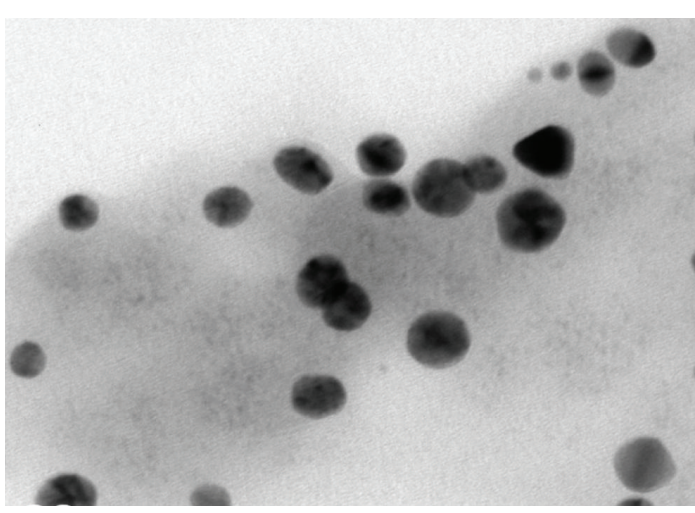

(a)

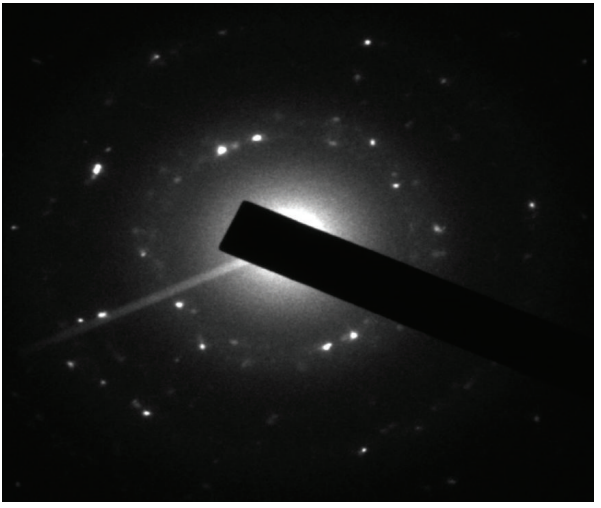

(c)

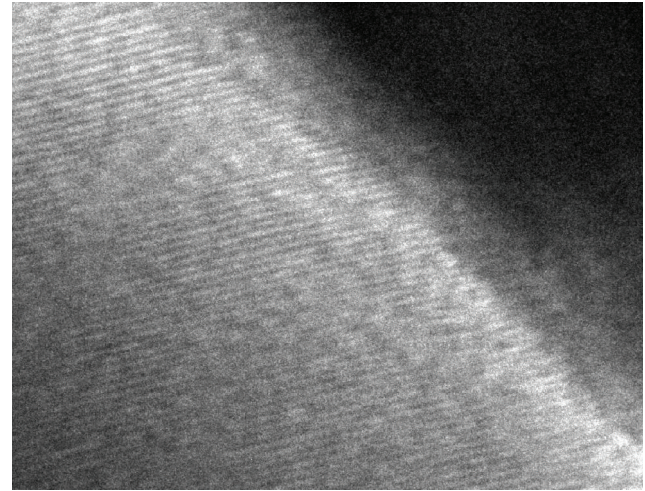

(b)

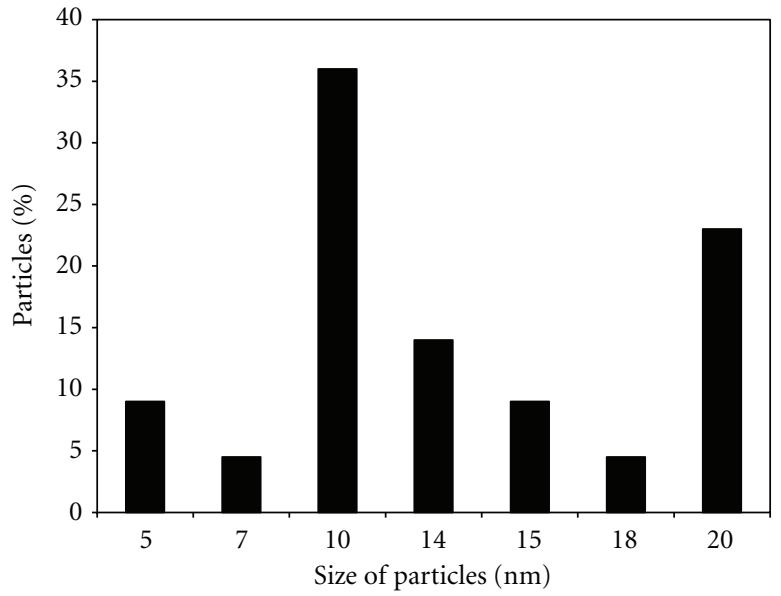

(d)

FIgure 3: Typical TEM image (a), with corresponding high resolution TEM view (b), SAED pattern (c), and size distribution (d) of GNPs synthesized from $3 \%$ procera latex with $1 \mathrm{mM} \mathrm{HAuCl}_{4}$ at $40 \mathrm{sec} \mathrm{MW}$ irradiation.

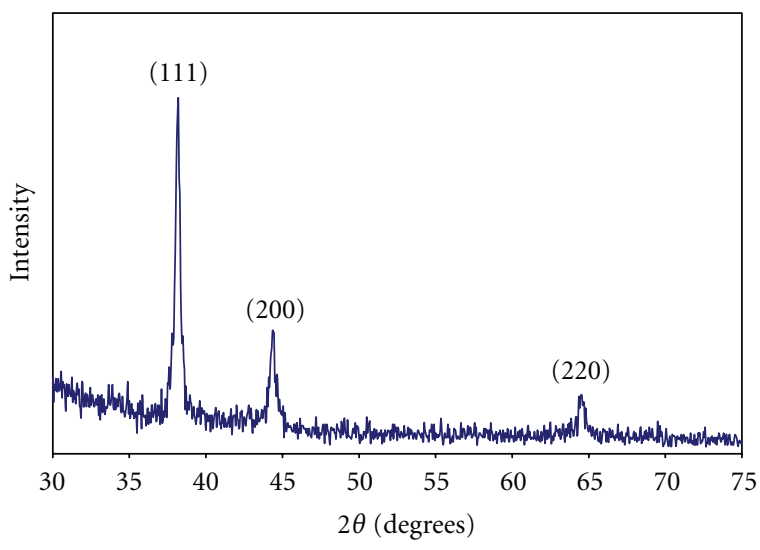

FIGURE 4: XRD pattern of the GNPs.

the presence of a protein coating on the GNPs. Cytotoxicity studies revealed that the GNPs were biocompatible due to the presence of the protein capping. The particles were stable

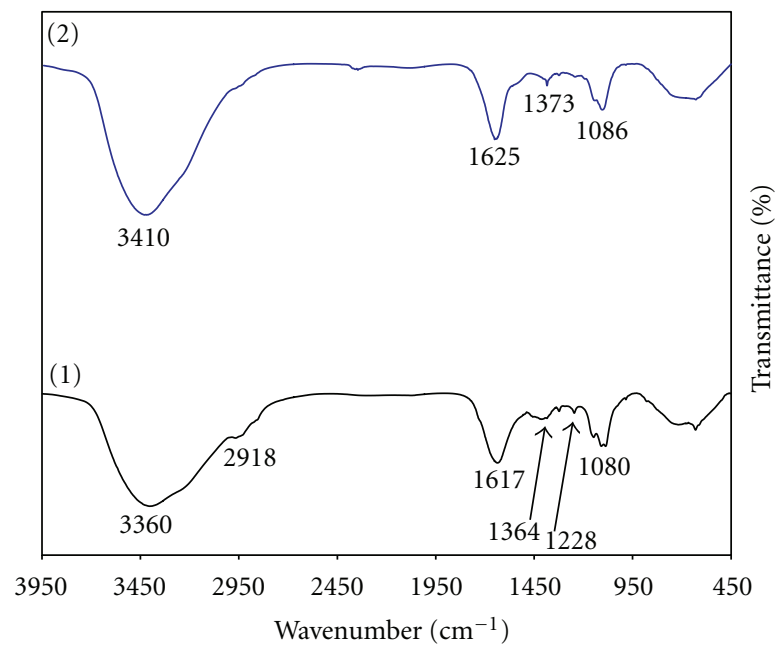

(1) LS

(2) Au-NP

FIGURE 5: FT-IR spectra of lyophilized AF (curve 1) and GNPs (curve 2). 


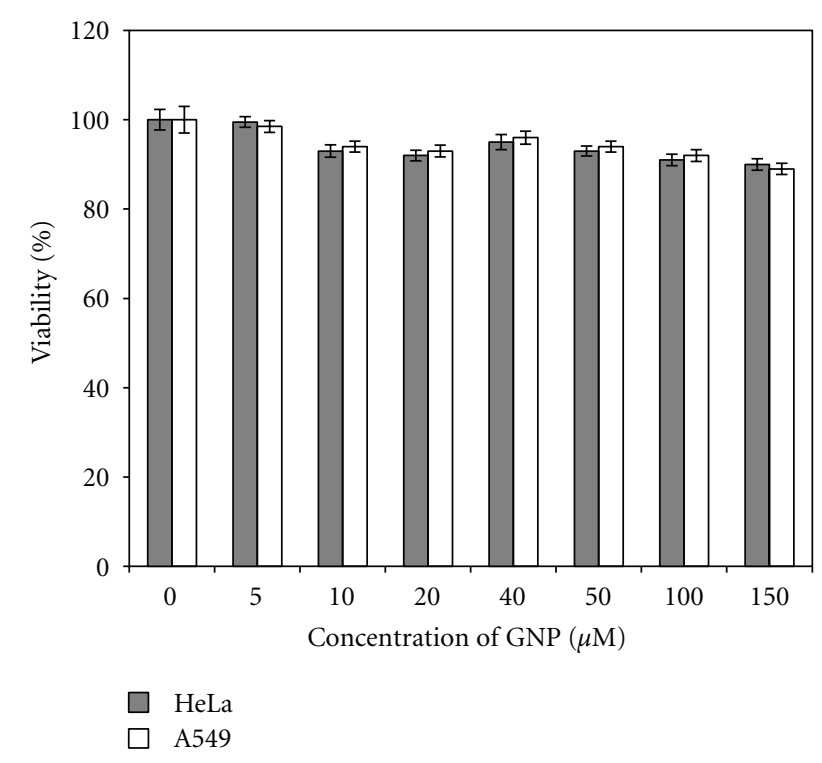

Figure 6: Cytotoxicity assay: cell viability of HeLa and A549 cells exposed to zero (control) or different micromolar concentrations of GNPs.

over six months without any appreciable change and could be ideal for biological applications.

\section{Disclosure}

This is to declare that the present work is not published anywhere or submitted elsewhere for the publication. All authors materially participated in present research work and there will not be any conflicts among authors in future.

\section{Authors' Contribution}

R. K. Das and P. J. Babu are contributed equally to this work.

\section{Acknowledgment}

The authors thank the Department of Biotechnology, Government of India, for funding this work (Sanction no. BT/04/ $\mathrm{NE} / 2009$ ).

\section{References}

[1] J. M. Thomas, "Colloidal metals: past, present and future," Pure and Applied Chemistry, vol. 60, no. 10, pp. 1517-1528, 1998.

[2] G. Schmid, "Large clusters and colloids. Metals in the embryonic state," Chemical Reviews, vol. 92, no. 8, pp. 1709-1727, 1992.

[3] L. N. Lewis, "Chemical catalysis by colloids and clusters," Chemical Reviews, vol. 93, no. 8, pp. 2693-2730, 1993.

[4] B. C. Gates, "Supported metal clusters: synthesis, structure, and catalysis," Chemical Reviews, vol. 95, no. 3, pp. 511-522, 1995.

[5] H. Hirai and N. Toshima, "ploymer-attached catalyst," in Tailored Metal Catalysts, Y. Iwasawa, Ed., pp. 121-140, Reidel, Dordrecht, The Netherlands, 1986.
[6] H. Bonnemann, W. Brijoux, R. Brinkmann et al., "Preparation, characterization, and application of fine metal particles and metal colloids using hydrotriorganoborates," Journal of Molecular Catalysis, vol. 86, no. 1-3, pp. 129-177, 1994.

[7] H. Liu, G. Mao, and S. Meng, "Preparation and characterization of the polymer-protected palladium-gold colloidal bimetallic catalysts," Journal of Molecular Catalysis, vol. 74, no. 1-3, pp. 275-284, 1992.

[8] W. Yu, Y. Wang, H. Liu, and W. Zheng, "Preparation and characterization of polymer-protected $\mathrm{Pt} / \mathrm{Co}$ bimetallic colloids and their catalytic properties in the selective hydrogenation of cinnamaldehyde," Journal of Molecular Catalysis A, vol. 112, no. 1, pp. 105-113, 1996.

[9] Y. Wang, H. Liu, and Y. Jiang, "A new method for immobilization of polymer-protective colloidal platinum metals via co-ordination capture with anchored ligands. Synthesis of the first example of a mercapto-containing supported metallic catalyst for hydrogenation of alkenes with high activity," Journal of the Chemical Society, Chemical Communications, no. 24, pp. 1878-1879, 1989.

[10] W. Y. Yu, H. F. Liu, and Q. Tao, "Modification of metal cations to metal clusters in liquid medium," Chemical Communications, no. 15, pp. 1773-1774, 1996.

[11] G. Schmid, S. Emde, V. Maihack, W. Meyer-Zaika, and S. Peschel, "Synthesis and catalytic properties of large ligand stabilized palladium clusters," Journal of Molecular Catalysis A, vol. 107, no. 1-3, pp. 95-104, 1996.

[12] R. F. Ziolo, E. P. Giannelis, B. A. Weinstein et al., "Matrixmediated synthesis of nanocrystalline $\gamma-\mathrm{Fe}_{2} \mathrm{O}_{3}$ : a new optically transparent magnetic material," Science, vol. 257, no. 5067, pp. 219-223, 1992.

[13] U. Simon, G. Schön, and G. Schmid, "Die Verwendung von Au55-Clustern als Quantenpunkte," Angewandte Chemie, vol. 32, no. 2, pp. 250-254, 1993.

[14] J. F. Hainfeld, D. N. Slatkin, T. M. Focella, and H. M. Smilowitz, "Gold nanoparticles: a new X-ray contrast agent," British Journal of Radiology, vol. 79, no. 939, pp. 248-253, 2006.

[15] C. Alric, J. Taleb, G. Le Duc et al., "Gadolinium chelate coated gold nanoparticles as contrast agents for both X-ray computed tomography and magnetic resonance imaging," Journal of the American Chemical Society, vol. 130, no. 18, pp. 5908-5915, 2008.

[16] Z. Zhang, R. C. Patel, R. Kothari, C. P. Johnson, S. E. Friberg, and P. A. Aikens, "Stable silver clusters and nanoparticles prepared in polyacrylate and inverse micellar solutions," Journal of Physical Chemistry B, vol. 104, no. 6, pp. 1176-1182, 2000.

[17] S. Chen, K. Huang, and J. A. Stearns, "Alkanethiolate-protected palladium nanoparticles," Chemistry of Materials, vol. 12, no. 2, pp. 540-547, 2000.

[18] A. Manna, T. Imae, M. Iida, and N. Hisamatsu, "Formation of silver nanoparticles from a N-hexadecylethylenediamine silver nitrate complex," Langmuir, vol. 17, no. 19, pp. 6000-6004, 2001.

[19] S. He, J. Yao, P. Jiang et al., "Formation of silver nanoparticles and self-assembled two-dimensional ordered superlattice," Langmuir, vol. 17, no. 5, pp. 1571-1575, 2001.

[20] R. K. Das, B. B. Borthakur, and U. Bora, "Green synthesis of gold nanoparticles using ethanolic leaf extract of Centella asiatica," Materials Letters, vol. 64, no. 13, pp. 1445-1447, 2010.

[21] P. Mohanpuria, N. K. Rana, and S. K. Yadav, "Biosynthesis of nanoparticles: technological concepts and future applications," Journal of Nanoparticle Research, vol. 10, no. 3, pp. 507$517,2008$. 
[22] P. Raveendran, J. Fu, and S. L. Wallen, "Completely "green" synthesis and stabilization of metal nanoparticles," Journal of the American Chemical Society, vol. 125, no. 46, pp. 1394013941, 2003.

[23] H. Huang and X. Yang, "Synthesis of polysaccharide-stabilized gold and silver nanoparticles: a green method," Carbohydrate Research, vol. 339, no. 15, pp. 2627-2631, 2004.

[24] P. Mukherjee, A. Ahmad, D. Mandal et al., "Fungus-mediated synthesis of silver nanoparticles and their immobilization in the mycelial matrix: a novel biological approach to nanoparticle synthesis," Nano Letters, vol. 1, no. 10, pp. 515-519, 2001.

[25] P. Mukherjee, A. Ahmad, D. Mandal et al., "Bioreduction of $\mathrm{AuCl}_{4}{ }^{-}$ions by the fungus, Verticillium sp. and surface trapping of the gold nanoparticles formed," Angewandte Chemie, vol. 40, pp. 3585-3588, 2001.

[26] Y. Xiao, V. Pavlov, S. Levine, T. Niazov, G. Markovitch, and I. Willner, "Catalytic growth of Au nanoparticles by $\mathrm{NAD}(\mathrm{P}) \mathrm{H}$ cofactors: optical sensors for $\mathrm{NAD}(\mathrm{P})+$-dependent biocatalyzed transformations," Angewandte Chemie, vol. 43, no. 34, pp. 4519-4522, 2004.

[27] P. J. Babu, P. Sharma, B. B. Borthakur, R. K. Das, P. Nahar, and U. Bora, "Synthesis of gold nanoparticles using Mentha arvensis leaf extract," International Journal of Green Nanotechnology, vol. 2, no. 2, pp. P62-P68, 2010.

[28] Y. Wada, H. Kuramoto, T. Sakata et al., "Preparation of nanosized nickel metal particles by microwave irradiation," Chemistry Letters, no. 7, pp. 607-608, 1999.

[29] Y. Wada, H. Kuramoto, J. Anand et al., "Microwave-assisted size control of CdS nanocrystallites," Journal of Materials Chemistry, vol. 11, no. 7, pp. 1936-1940, 2001.

[30] H. Yin, T. Yamamoto, Y. Wada, and S. Yanagida, "Large-scale and size-controlled synthesis of silver nanoparticles under microwave irradiation," Materials Chemistry and Physics, vol. 83, no. 1, pp. 66-70, 2004.

[31] K. Patel, S. Kapoor, D. P. Dave, and T. Mukherjee, "Synthesis of nanosized silver colloids by microwave dielectric heating," Journal of Chemical Sciences, vol. 117, no. 1, pp. 53-60, 2005.

[32] P. Nahar and U. Bora, "Microwave-mediated rapid immobilization of enzymes onto an activated surface through covalent bonding," Analytical Biochemistry, vol. 328, no. 1, pp. 81-83, 2004.

[33] A. Sahu, P. Goswami, and U. Bora, "Microwave mediated rapid synthesis of chitosan," Journal of Materials Science, vol. 20, no. 1, pp. 171-175, 2009.

[34] J. M. Thiebaut, G. Roussy, M. S. Medjram, F. Garin, L. Seyfried, and G. Maire, "Durable changes of the catalytic properties of alumina-supported platinum induced by microwave irradiation," Catalysis Letters, vol. 21, no. 1-2, pp. 133-138, 1993.

[35] R. Correa, G. Gonzalez, and V. Dougar, "Emulsion polymerization in a microwave reactor," Polymer, vol. 39, no. 6-7, pp. 1471-1474, 1998.

[36] H. Yin, T. Yamamoto, Y. Wada, and S. Yanagida, "Large-scale and size-controlled synthesis of silver nanoparticles under microwave irradiation," Materials Chemistry and Physics, vol. 83, no. 1, pp. 66-70, 2004.

[37] K. Patel, S. Kapoor, D. P. Dave, and T. Mukherjee, "Synthesis of nanosized silver colloids by microwave dielectric heating," Journal of Chemical Sciences, vol. 117, no. 1, pp. 53-60, 2005.

[38] R. K. Das, P. Sharma, P. Nahar, and U. Bora, "Synthesis of gold nanoparticles using aqueous extract of Calotropis procera latex," Materials Letters, vol. 65, no. 4, pp. 610-613, 2011.

[39] O. H. Lowry, N. J. Rosebrough, A. L. Farr, and R. J. Randall, "Protein measurement with the Folin phenol reagent," The
Journal of Biological Chemistry, vol. 193, no. 1, pp. 265-275, 1951.

[40] M. Horisberger and M. Vauthe, "Labelling of colloidal gold with protein," Histochemistry, vol. 80, no. 1, pp. 13-18, 1984.

[41] T. Mosmann, "Rapid colorimetric assay for cellular growth and survival: application to proliferation and cytotoxicity assays," Journal of Immunological Methods, vol. 65, no. 1-2, pp. 55-63, 1983.

[42] C. Basset, J. Vadrot, J. Denis, J. Poupon, and E. S. Zafrani, "Prolonged cholestasis and ductopenia following gold salt therapy," Liver International, vol. 23, no. 2, pp. 89-93, 2003.

[43] C. Frank Shaw III, "Gold-based therapeutic agents," Chemical Reviews, vol. 99, no. 9, pp. 2589-2600, 1999. 

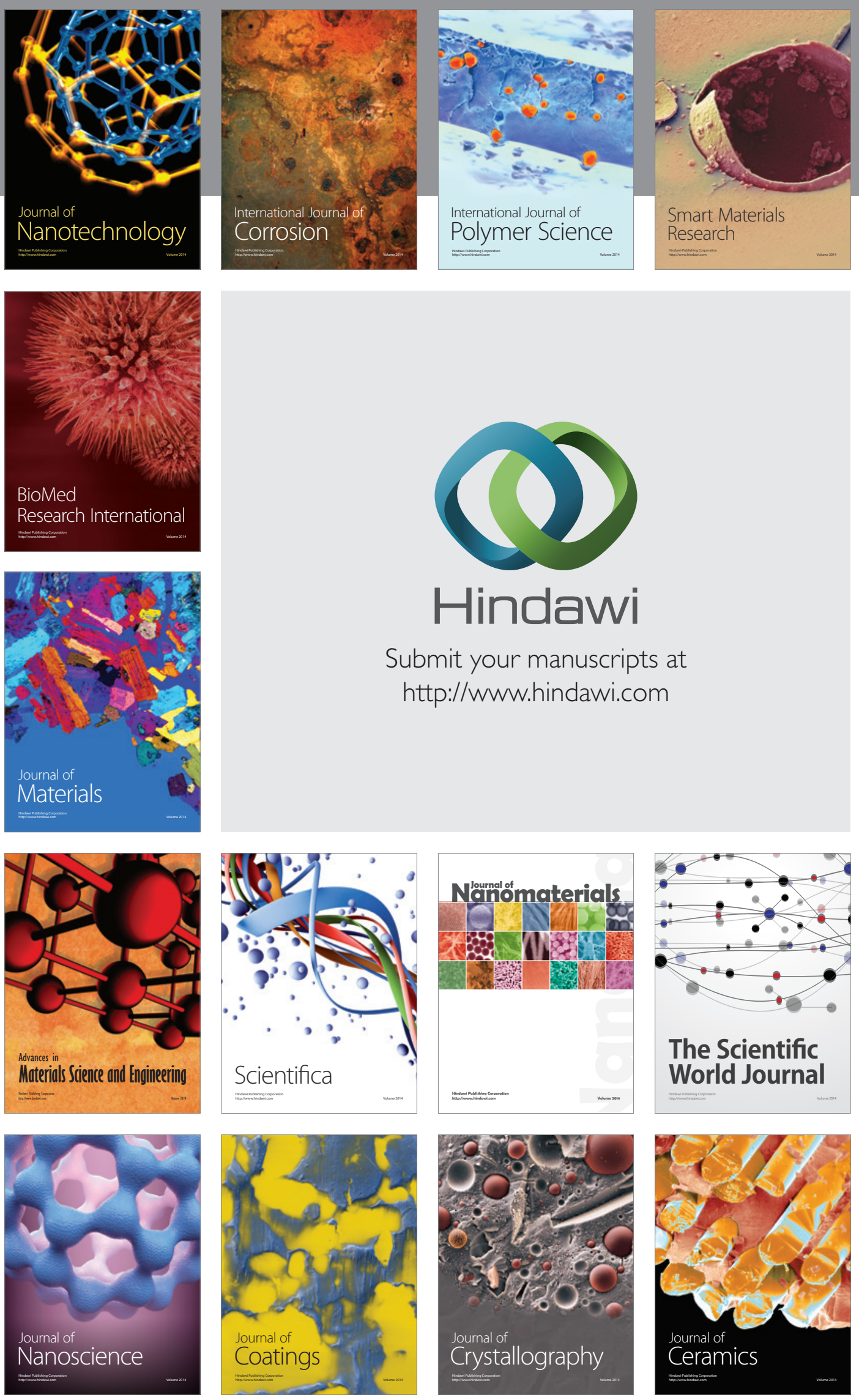

The Scientific World Journal

Submit your manuscripts at

http://www.hindawi.com

\section{World Journal}

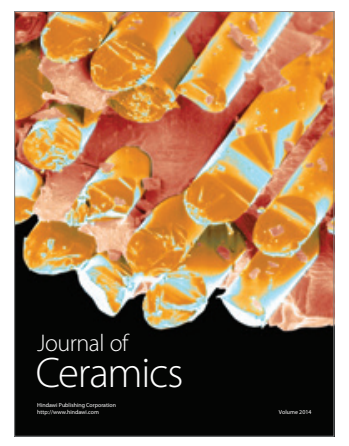

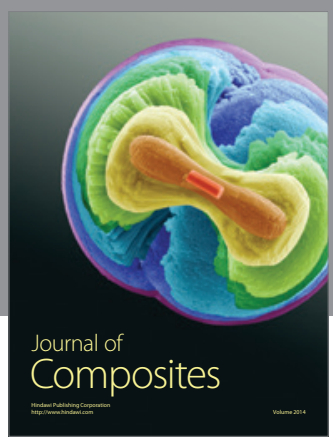
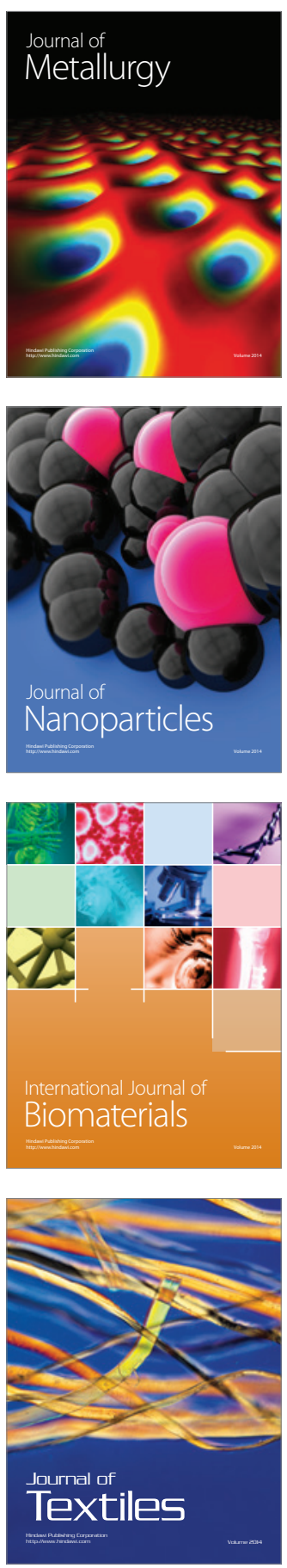